\title{
Organisation of the dopamine neuronal subsets within midbrain of the feathertail glider (Acrobates pygmaeus, Acrobatidae, Marsupialia)
}

\author{
R. Krawczyk ${ }^{1}$, I. Klejbor ${ }^{1,2}$, K. Turlejski³ , B. Ludkiewicz' ${ }^{1}$, J. Moryś'1, 2 \\ ${ }^{1}$ Department of Anatomy and Neurobiology, Medical University of Gdansk, Poland \\ 2Institute of Health Sciences, Pomeranian University of Slupsk, Poland \\ ${ }^{3}$ Department of Biology and Environmental Sciences, Cardinal Stefan Wyszynski University, Warsaw, Poland
}

[Received: 20 September 2017; Accepted: 15 October 2017]

The Marsupial feathertail glider has a unique set of morphological, anatomical and behavioural features that make it a promising model for study of primate evolution. Among them it has many locomotor adaptations to arboreal life, such as diagonal gait of movements, gliding, fast climbing and running along branches. These ecological and behavioural specialisations could result in differences in anatomy of the brain systems involved in their integration. It is well acknowledged that dopaminergic neurons are involved in motor control, motivation and cognition. Due to the fact that there are no data on morphological organisation of dopaminergic system in the midbrain of this species, we decided to investigate it using immunohistochemical and quantitative methods. Our study showed that the general distribution and characteristics of the dopaminergic cells within midbrain nuclei of the pygmy acrobat is similar to that in other species, but it lack the substantia nigra compact part - ventral tier and "tail" of the substantia nigra subnuclei. This study provides the first description of the dopaminergic cells and nuclei in the midbrain of the feathertail glider and we hope it will start interest in the neurobiology of this species. (Folia Morphol 2017; 76, 4: 558-567)

Key words: feathertail glider, marsupial, dopaminergic neurons, midbrain nuclei, immunohistochemistry

\section{INTRODUCTION}

The feathertail glider (Acrobates pygmaeus) is the smallest gliding mammal in the world $[21,64$, $69,77]$. It inhabits the mainland forests and shrubby woodland ranging widely along the Australian eastern coast from Northern Queensland to Southern Australia $[64,77]$. The natural habitats of this species are the canopies of tall, well-watered coastal eucalyptus forests, as well as lower sclerophyl forests and dense dry shrubs inland from the coast. Feathertail glider is mainly a nocturnal species, able to fell in torpor during cold days and when active spending up to $87 \%$ of its time in trees at heights greater than $15 \mathrm{~m}$, which makes it the most mysterious and rarest seen of all gliding mammals [21,64]. The diet of this species consists of plants' nectar, tree saps and small insects. It is the only mammal possessing stiff feather-like hairs along the sides of its long tail that form a flattened tail-feather. This flat tail surface gives the feathertail glider an excellent ability to control the flight path between tree trunks and among branches $[64,72,77]$. The tail can also be used for grasping branches [64]. This species has also lateral folds of skin stretching between elbow and knee on both

Address for correspondence: I. Klejbor, PhD, Department of Anatomy and Neurobiology, Medical University of Gdańsk, ul. Dębinki 1, 80-210 Gdańsk, Poland, e-mail: klejbor@gumed.edu.pl 
sides known as a "patagium" that increases its gliding ability $[19,64]$. Among branches and along trunks it moves swiftly with a diagonal gait resembling that of climbing primates [39]. What more, this species has the ability to run up and down smooth surfaces. This ability is related to the unique structure of their feet which resemble gecko feet. The large pads on its toes have serrated grooves underneath and can act like mini suction cups. This adaptation allows the glider to climb up just about any surface, including smooth-barked eucalyptus tree-trunks and window glass $[63,64,72,77$, Y. Werner, personal communication]. These reports clearly show that this small marsupial species has unique anatomical adaptations to moving in different ways (gliding, climbing, running, jumping among branches) and exhibits high locomotor activity.

Specific behavioural adaptations, such as diverse locomotor activity, may depend on differences in anatomy and physiology of the brain circuits that are involved in the control and integration of behaviour $[38,65,73]$. It is worth noting that dopamin is a major neurotransmitter involved in the modulation of different behaviours, in particular, motor activity of animals and also plays a crucial role in positive motivation of animal behaviour and its adaptation to changing environment in the course of evolution $[35,66,75,78]$. Dopaminergic neurons which are involved in motor control, motivation and cognition, are also crucial in aetiology of some disorders, such as Parkinson's disease or schizophrenia.

Dopaminergic neurons are-distributed in several midbrain structures such as the ventral tegmental area (VTA), substantia nigra (SN) and retrorubral field $[2,13$, $14,20,22,54,67]$. As there are no data on morphological organisation of the dopaminergic system in the midbrain of the Acrobates pygmaeus, we decided to investigate it using immunohistochemical and quantitative methods. Such data are interesting from both physiological and comparative points of view helping to understand the specific behaviour of this species, such as diverse locomotor activity or gliding flight $[1,21,72]$.

\section{MATERIALS AND METHODS}

\section{Animals}

In this study, we used eight brains of male adult A. pygmaeus (Acrobatidae, Diprotodontia). The brains were obtained from the Poznan New ZOO, Poland, as post-sectional material (heads) from males that had to be sacrificed for ZOO animal husbandry reasons and purposes. In 2008 and 2009 the ZOO certified the donation of the Acrobates heads to prof. Krzysztof Turlejski, to be used in his basic research. In Poland, such a form of post-mortem use of animal cadavers does not require opinion or agreement of an Ethics Committee.

\section{Immunohistochemistry}

Brains of the Acrobates pygmaeus were quickly removed from skulls and postfixed in $4 \%$ paraformaldehyde for 3-4 days. Then, they were placed in 15\% sucrose solution (overnight at $4^{\circ} \mathrm{C}$ ) followed by $30 \%$ sucrose solution until they sunk. After this, coronal $40 \mu \mathrm{m}$-thick sections of the brain were cut on cryostat (Leica, Germany). Separate alternate series of sections were collected for Nissl and immunohistochemical staining. Nissl staining was performed in accordance with the standard protocols, whereas labeling with antibodies against tyrosine hydroxylase were used for immunohistochemistry protocol. Sections were washed three times in $0.01 \mathrm{M}$ phosphate buffered saline (PBS) followed by $2.5 \mathrm{~h}$ blocking in $10 \%$ normal goat serum and $0.3 \%$ Triton $\mathrm{X}-100$ at room temperature. Then, the sections were incubated for $48 \mathrm{~h}$ in $4^{\circ} \mathrm{C}$ with the primary antibodies against tyrosine hydroxylase (1:1000, Millipore). Afterward, sections were washed 3 times in PBS and incubated for $2.5 \mathrm{~h}$ with the secondary antibodies: 1:600 goat anti-rabbit antibody for tyrosine hydroxylase conjugated with Cy3 (111-165-144 Jackson ImmunoResearch Laboratories). The sections were then washed, mounted on slides and cover-slipped with Kaiser's Glycerol gelatin for microscopy (Merck).

\section{Quantitative study}

Every fourth systematic random sampling section containing VTA-SN complex and A8 dopaminergic cell group was chosen. The delineation of A8 and subdivisions of the ventral tegmental area and the substantia nigra were prepared using Fu et al. [23] and Paxinos and Watson [58]. Following Gundersen [30], we estimated: (1) the number of profiles per area (QA); (2) the area of profiles (AA); (3) the mean profile area $(\bar{a})$.

1. $Q A_{(\text {proftsect) }}=Q_{(\text {prof })} / A_{(\text {sect) }}-$ number of profiles per area of frame

2. $\mathrm{AA}_{\text {(structsect) }}=\Sigma \mathrm{P}_{\text {(struct) }} / \Sigma \mathrm{P}_{\text {(sect) }}-$ total area of structure/total area of section

3. $\bar{a}_{\text {(prof) }}=A A_{\text {(prot/sect) }} / \mathrm{QA}_{\text {(prot/sect) }}$ - relative area of profiles/relative number of profiles 


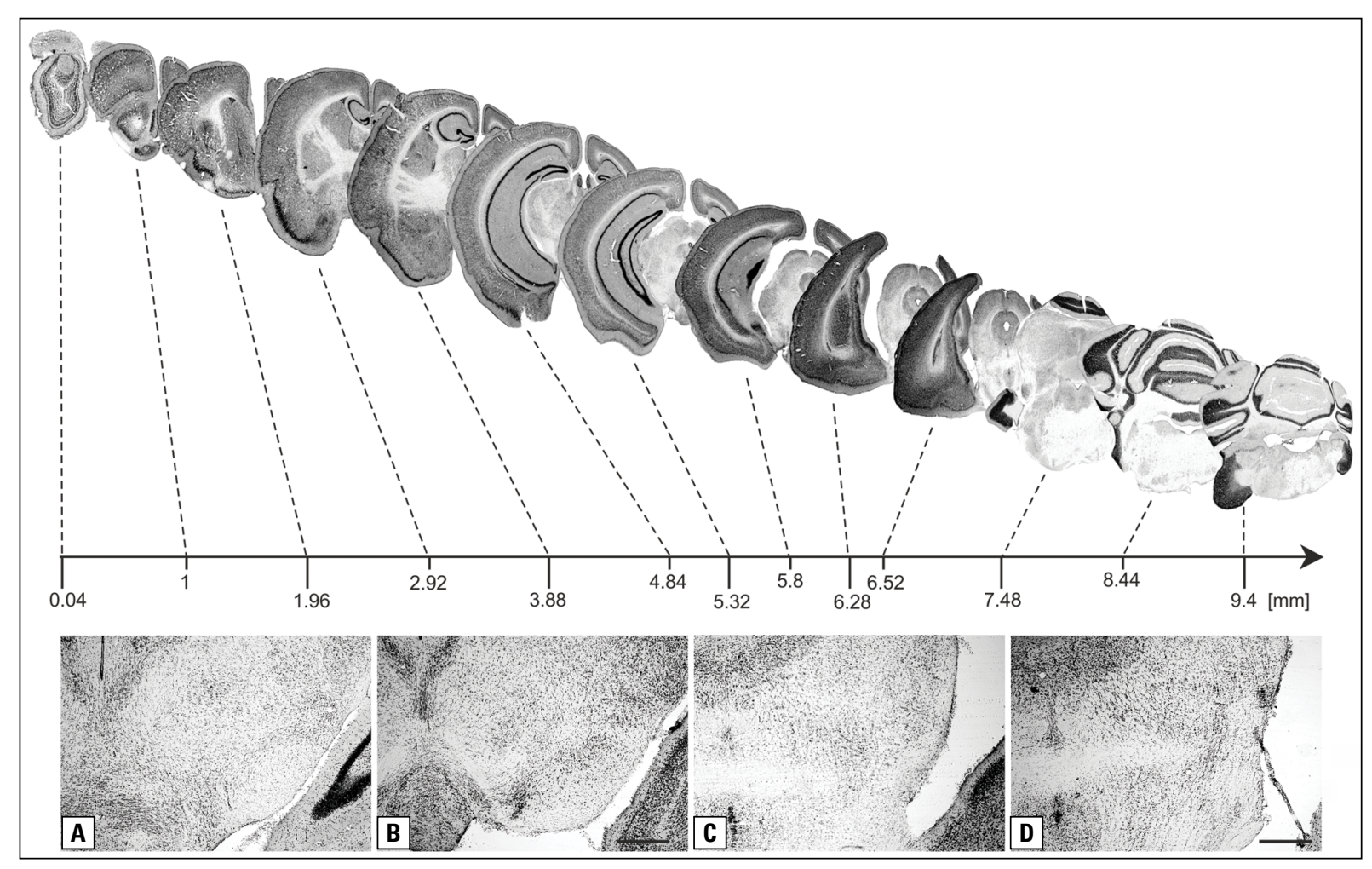

Figure 1. Nissl staining of coronal sections in the rostral to caudal order from the Acrobates pygmaeus brain. Axis shows the distance between subsequent sections in millimetres $(\mathbf{A})$. Representative Nissl staining photomicrographs of substantia nigra-ventral tegmental area (SN-VTA) complex and retrorubral field for $5.32 \mathrm{~mm}$ (B), $5.8 \mathrm{~mm}$ (C), $6.28 \mathrm{~mm}$ (D). Scale bar relates to A-D pictures $=500 \mu \mathrm{m}$.

TH-immunoreactive cells with visible nuclei were quantified using the new CAST software (Visiopharm, Denmark) connected with Olympus BX51 microscope. The microscope was equipped with Olympus DP72 camera (Olympus, Japan). The recognition of the regions of interest was achieved at $4 \times$ lens and quantification of profiles of cells at $40 \times$. The results were estimated from 50 to 60 testing areas and 100-200 counted cells per structure, or less if it was not possible to count this many.

\section{RESULTS}

\section{Cytoarchitecture of the VTA-SN complex} and retrorubral field

The investigated substantia nigra, ventral tegmental area, and retrorubral field (A9, A10 and A8 dopaminergic cell groups, respectively) of Acrobates pygmaeus extend for $5.0-6.7 \mathrm{~mm}$ in the rostocaudal direction (Fig. 1).

\section{Distribution of tyrosine hydroxylase in the A9 dopaminergic cell group}

We identified four subdivisions of the substantia nigra: substantia nigra compact part - dorsal tier
(SNCD), substantia nigra compact part - lateral tier (SNCL), substantia nigra compact part - medial tier (SNCM), and substantia nigra reticular part (SNR). In the present study, we did not find $\mathrm{TH}$-immunoreactive neurons corresponding to the substantia nigra compact part - ventral tier (SNCV).

The SNCD is located over the SNR (Fig. 2A-E) and contains $\mathrm{TH}$-ir neurons packed in moderate density $(\mathrm{QA}=276.6 \pm 162.5, \mathrm{AA}=0.06 \pm 0.01)$, with the largest cells of all studied TH-ir cell groups (231.1 \pm $\pm 52.8 \mu \mathrm{m}^{2}$ ) and predominantly multipolar, round or triangular neurons with frequently branched dendrites. Many of the dendrites extended ventromedially and ventrolaterally into the SNR (Fig. 3B). TH-immunoreactive cells located laterally to the $S N C D$ belonged to the SNCL and were highly variable (Fig. 2B-E). These neurons were generally small (184.2 $\left.\pm 39.3 \mu \mathrm{m}^{2}\right)$, fusiform, round or triangular, and loosely packed $(\mathrm{QA}=150.6 \pm 64.2, \mathrm{AA}=0.03 \pm 0.01)$.

Bipolar and multipolar cells had thin processes. Some of their dendrites coursed into the lateral part of SNR (Fig. 3A). A medial extension of the SNCD is the substantia nigra compact part medial tier 

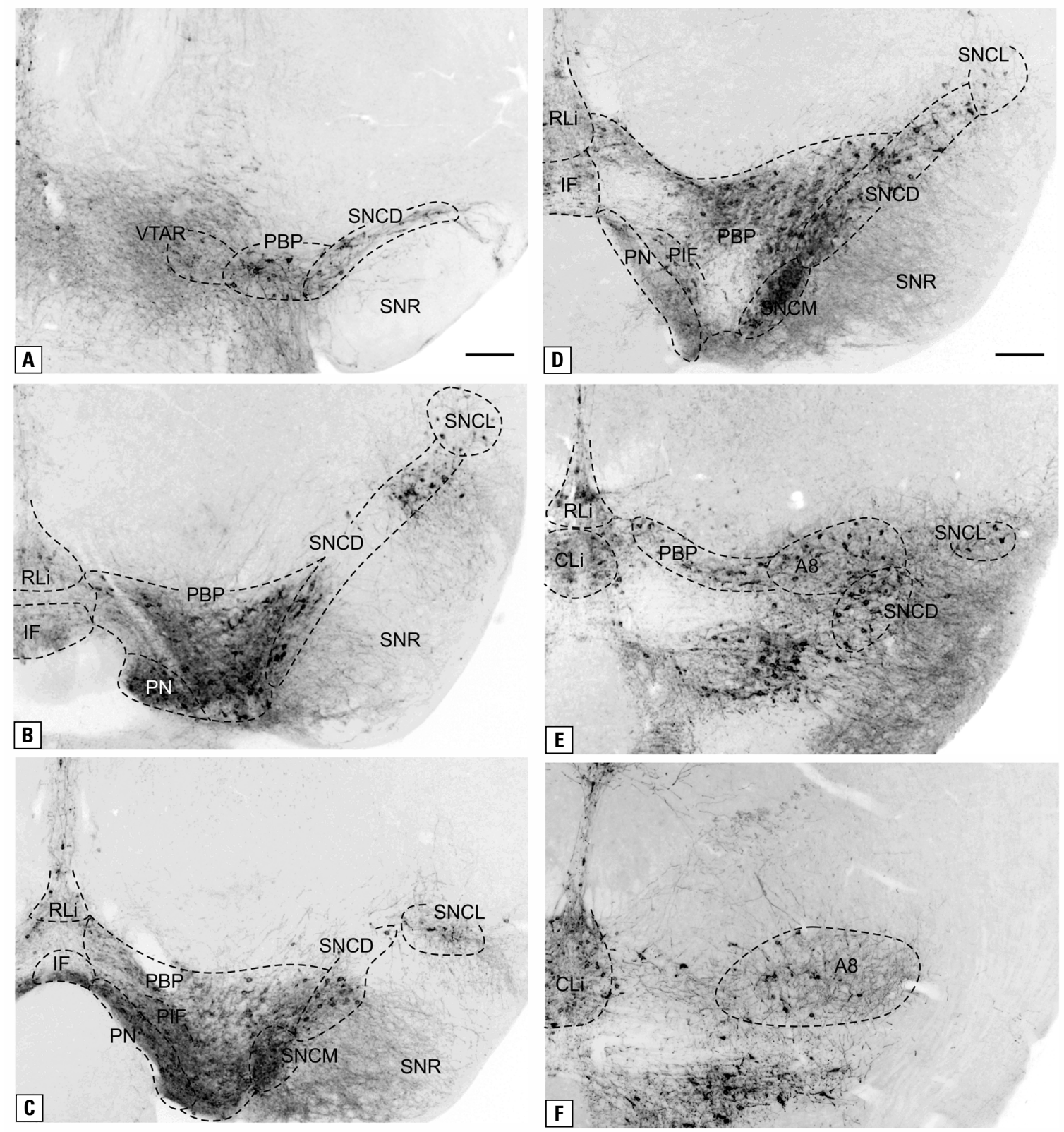

Figure 2. The photomicrographs of coronal sections of the Acrobates pygmaeus midbrain. Low-power illustrations A-F show distribution of tyrosine hydroxylase-immunoreactivity in particular nuclei. Substantia nigra compact part dorsal tier (SNCD), substantia nigra compact part lateral tier (SNCL), substantia nigra compact part medial tier (SNCM), substantia nigra reticular part (SNR), ventral tegmental area rostral part (VTAR) parabrachial pigmented nucleus (PBP), parainterfascicular nucleus (PIF), paranigral nucleus (PN), interfascicular nucleus (IF), rostral linear nucleus (RLi), caudal linear nucleus of the raphe (CLi) and A8 dopaminergic cell group (A8). Scale bar relates to all pictures $=200 \mu \mathrm{m}$.

(Fig. 2C, D). In the SNCM, neurons were the most densely packed from all of the investigated nuclei $(\mathrm{QA}=883.3 \pm 183.4$ and $\mathrm{AA}=0.18 \pm 0.05$, respectively). They ranged in size, primarily from middle to big $\left(215.4 \pm 57.1 \mu \mathrm{m}^{2}\right)$ multipolar cells with densely spread dendrites, of which extended into the medial part of SNR (Fig. 3C). In most cases their neuronal bodies had round or fusiform shape.

\section{Distribution of tyrosine hydroxylase in the $\mathrm{A} 10$ dopaminergic cell group}

In the VTA area we were able to distinguish following nuclei: ventral tegmental area rostral part (VTAR) parabrachial pigmented nucleus (PBP), parainterfascicular nucleus (PIF), paranigral nucleus (PN), interfascicular nucleus (IF), rostral linear nucleus (RLi) and caudal linear nucleus of the raphe (CLi). For quantifi- 

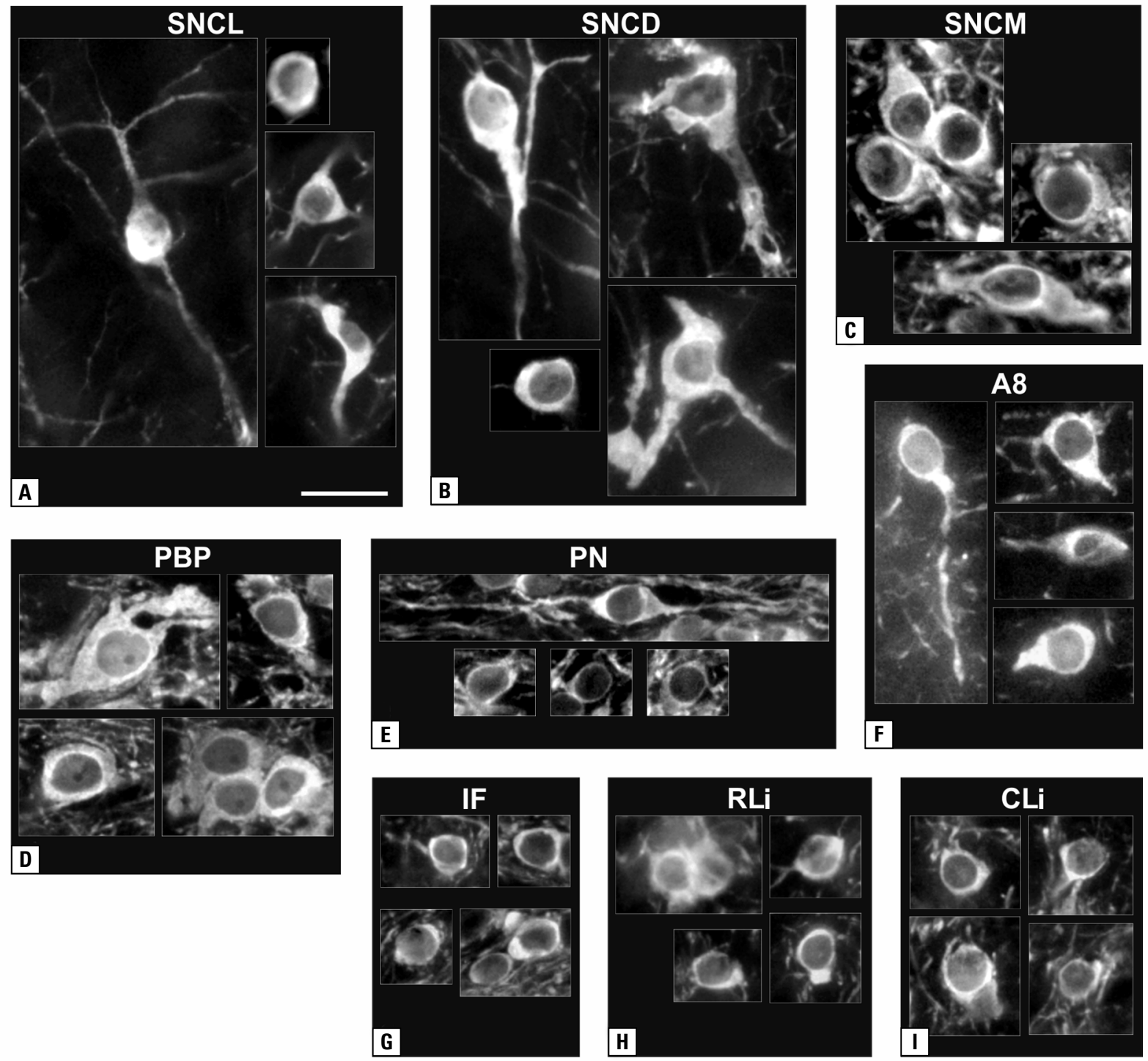

Figure 3. High-power photomicrographs show morphology of tyrosine hydroxylase-immunoreactivity in neurons. A. Substantia nigra compact part lateral tier (SNCL); B. Substantia nigra compact part dorsal tier (SNCD); C. Substantia nigra compact part medial tier (SNCM); D. Parabrachial pigmented nucleus (PBP); E. Paranigral nucleus (PN); F. A8 dopaminergic cell group (A8); G. Interfascicular nucleus (IF); H. Rostral linear nucleus (RLi); I. Caudal linear nucleus of the raphe (CLi). Scale bar relates to all pictures $=20 \mu \mathrm{m}$.

cation and qualitative studies, we incorporated VTAR to PBP and PIF to PN, because there were too few sections across these nuclei to perform the analysis.

The PBP is a wing-shaped structure located most laterally of all VTA nuclei (Fig. 2A-E). Tyrosine hydroxylase labeled neurons in the PBP were primarily bipolar, medium sized $\left(227.5 \pm 25 \mu \mathrm{m}^{2}\right)$, polygonal, oval or round with variably oriented dendrites and moderate density $(\mathrm{QA}=196.6 \pm 61, \mathrm{AA}=0.04 \pm 0.01$ (Fig. 3D). Large multipolar, triangular or polygonal cells were uniformly scattered. The PN is a small, elongated structure formed by cells located medially to the parabrachial pigmented nucleus (Fig. 2B-D). Neurons found in the PN were small $\left(159.6 \pm 16.9 \mu \mathrm{m}^{2}\right)$ and densely packed ( $\mathrm{QA}=491.4 \pm 247.8, \mathrm{AA}=$ $=0.08 \pm 0.04$ ), fusiform or oval, with long and smooth processes directed dorsomedially (Fig. 3E). Three nuclei of the VTA: IF, RLi and CLi located at the midline (Fig. 2B-F) were similar in their morphology. They contained small, round cells $(144.8 \pm 17.8,149.6 \pm$ $\pm 14.9,153.8 \pm 15.4 \mu \mathrm{m}^{2}$ for IF, RLi and CLi, respectively) with large, clearly visible nucleus. Neuronal dendrites were poorly branched with variable organisation (Fig. 3G-I). Evaluation of the density of the cells revealed differences between the structures. Neuronal density in the CLi and IF was moderate to high $(\mathrm{QA}=232.1 \pm 69.8, \mathrm{AA}=0.03$ for $\mathrm{CLi}$ and $\mathrm{QA}=284 \pm$ $\pm 118, A A=0.04 \pm 0.01$ for $(\mathrm{F}$, respectively) whereas 
in the RLi labeled cells were found in low density $(\mathrm{QA}=100 \pm 41.8, \mathrm{AA}=0.01 \pm 0.01)$.

\section{Distribution of tyrosine hydroxylase in the A8 dopaminergic cell group}

The A8 group neurons have moderate size $\left(213.4 \pm 20.5 \mu \mathrm{m}^{2}\right)$, oval or triangular shape, with loosely packed dendrites. This group is formed by sparsely scattered cell bodies (Fig. 2E, F; Fig. 3F). In contrast to other tyrosine hydroxylase-expressing cell groups, within A8 group the lowest density of neurons was found of all studied nuclei $(\mathrm{QA}=54 \pm 11, \mathrm{AA}=0.01 \pm 0.00$ ).

\section{DISCUSSION}

Our current research based on TH-immunohistochemical staining provides the first report about the morphometry, distribution and organisation of the dopaminergic cells within the A9, A10 and A8 nuclei in the midbrain of the marsupial Acrobates pygmaeus. We used tyrosine hydroxylase staining because many neurobiological researches prove that TH is a key enzyme for dopamine synthesis in the midbrain, making $\mathrm{TH}$ a reliable dopamine marker in this area. The VTA-SN complex and retrorubral field have been previously studied in various species of placental mammals $[3,4,6,8-12,16,17,23-25,27,33,34$, $40-43,46-53,55,59-61,68,70,76]$. These previous studies, mainly referring to the rodents, showed that individual variability, lifestyle, and evolutionary trends do not lead to a significant variation of dopaminergic nuclei between species belonging to the same order, but described subtle differences in the structure of dopaminergic nuclei between different orders of the placental mammals [45].

Despite these numerous studies describing anatomical and morphological organisation of the dopaminergic system of the placental mammals, data performed on Marsupials are more general and limited to species from the family Didelphidae (opossums) living in Southern and Northern America $[5,15,32,44]$. For example, Klejbor et al. [37] investigated distribution and morphology of the neurons expressing $\mathrm{TH}$ and calretinin in the midbrain nuclei: VTA, SN and periaqueductal gray (PAG) of the laboratory, grey short-tailed opossums a small, nocturnal marsupial native to Brazil and Bolivia [36, 74]. These studies showed that its dopaminergic cells are heterogeneous in morphology and chemistry, which may be related to the ability of this species to adapt to environmental challenges with its variable motor functions.
Simpler anatomical organisation of the Acrobates pygmaeus A9 dopaminergic cell group

Substantia nigra is divided into two main parts, ventrally located SNR and dorsally SNC $[56,71]$. Based on the TH immunohistochemistry, SNC might be further subdivided into four tiers: dorsal, lateral, medial and ventral, respectively $[23,29,57,62]$. In our current study, we did not find a region related to the rodents' SNCV described by Gerfen et al. [26], which is located in the caudal SN. As far as we know, this is the first report on the lack of ventral tier of the SNC in Acrobates pygmaeus.

Ventral tier of the SN is the main source of nigrostriatal neurons, projecting to the striatal patches, which regulate basal ganglia information processing. Disruption of these pathways causes motor dysfunctions. For example, movement disorders in Parkinson's disease are related to selective loss of dopaminergic neurons in the SN [7]. It has been shown that dopaminergic cells' degeneration starts and is more strongly expressed in the SNCV than in the SNCD $[18,28]$. In addition, this area in rodents and primates differs. Hardman et al. [31] showed that rat's SNCV is relatively smaller than in primates. These results have been recently confirmed in studies on a mouse [23], rock cavy [11] and bat [51]. With regard to these many reports, one of the possible explanations of our results is that the Marsupial's striatonigral dopaminergic system has simpler organisation. Our data have shown that the organisation of the substantia nigra in Acrobates pygmaeus is different than in rodents. Two morphologically distinctive dopaminergic tiers of the SN are not separated into different anatomical compartments: SNCV and SNCD, but are present as one tier. Our hypothesis about the simplified organisation of the substantia nigra in Acrobates pygmaeus seems to be supported by Gerfen et al. [26] connectivity study. Other studies [32] describing connections of midbrain dopaminergic neurons of another marsupial species (North American Dydelphis opossum) also confirmed that although the general organisation of midbrain neurons in the opossum is similar to the placental mammals, it is clear that differences exist.

Furthermore, we could not recognise $\mathrm{TH}$ cell group named the "tail" of the SNC (tSN) that was reported in some species $[12,51,55]$. Morphological features of the dopaminergic SN neurons are generally comparable and similar to those described previously in other species, especially SNCL $[23,32,37,44,51]$, which suggests high evolutionary conservatism of this 
tier. In the SN, the TH-positive neurons with largest somas are located in the SNC, which corresponds to results of other studies $[23,37,51]$. Surprisingly, differences were also noted in the medial tier of SN in the mouse and bat dopaminergic neurons in the SNCM are relatively small, whereas we found mainly large cells.

\section{Organisation of the $\mathrm{A} 8$ and $\mathrm{A} 10$ dopaminergic cell} groups is highly similar to that in other species

Ventral tegmental area in the Acrobates pygmaeus midbrain exhibits similarities to this region in rodents $[23,49,58]$. We were able to delineate all seven nuclei: CLi, IF, PBP, PIF, PN, RLi and VTAR. Unlike in the pygmy acrobat $\mathrm{SN}$, in the VTA we did not find any anatomical differences with other species. Careful analysis of VTA organisation reported in other species, including Marsupials, let us conclude, that despite adoption of different nomenclature, all nuclei are arranged in the same rostro-caudal and latero-medial order $[23,32,37,50,51]$.

Morphometric analysis has revealed general consistency of organisation among species [23, 37, 51]. However, small differences have been noted. However, small difference has been noted. Medeiros et al. [51] have shown relatively small neurons in the PBP compered to our results and study on mice [23], where have been found mostly large neurons. Some remaining minor differences might come from distinct methodological strategies.

A8 dopaminergic cell group is a dorso-caudal continuation of the pygmy acrobat SNC. Cells were mostly middle to large in size, what is consistent with previous reports in the mouse and bat $[23,51]$. We found that tyrosine hydroxylase neurons of the $A 8$ cell group was the smallest fraction of the dopaminergic neurons. Similar findings have been shown in a monkey, only $10 \%$ of neurons in the A8-A10 cell groups belong to the retrorubral field [22].

\section{CONCLUSIONS}

In conclusion, general distribution and characteristics of the dopaminergic cells within midbrain nuclei of the feathertail glider are similar to those in other species. Our results do not challenge this general model, in spite of some variations like the above-mentioned lack of the SNCV and tSN, while they significantly broaden our knowledge of neuroanatomy of this area in the species and provide a basis for its functional study.

\section{REFERENCES}

1. Aitkin LM, Nelson JE. Peripheral and central auditory specialization in a gliding marsupial, the feathertail glider, Acrobates pygmaeus. Brain Behav Evol. 1989; 33(6): 325-333, indexed in Pubmed: 2765851.

2. Björklund A, Dunnett SB. Dopamine neuron systems in the brain: an update. Trends Neurosci. 2007; 30(5): 194-202, doi: 10.1016/j.tins.2007.03.006, indexed in Pubmed: 17408759.

3. Bhagwandin A, Fuxe K, Bennett NC, et al. Nuclear organization and morphology of cholinergic, putative catecholaminergic and serotonergic neurons in the brains of two species of African mole-rat. J Chem Neuroanat. 2008; 35(4): 371-387, doi: 10.1016/j.jchemneu.2008.02.005, indexed in Pubmed: 18407460.

4. Blessing WW, Chalmers JP, Howe PR. Distribution of catecholamine-containing cell bodies in the rabbit central nervous system. J Comp Neurol. 1978; 179(2): 407-423, doi: 10.1002/cne.901790210, indexed in Pubmed: 641225 .

5. Brückner G, Pavlica S, Morawski M, et al. Organization of brain extracellular matrix in the Chilean fat-tailed mouse opossum Thylamys elegans (Waterhouse, 1839). J Chem Neuroanat. 2006; 32(2-4): 143-158, doi: 10.1016/j. jchemneu.2006.08.002, indexed in Pubmed: 16996716.

6. Bux F, Bhagwandin A, Fuxe K, et al. Organization of cholinergic, putative catecholaminergic and serotonergic nuclei in the diencephalon, midbrain and pons of sub-adult male giraffes. J Chem Neuroanat. 2010; 39(3): 189-203, doi: 10.1016/j.jchemneu.2009.09.006, indexed in Pubmed: 19808092.

7. Cacabelos R. Parkinson's disease: from pathogenesis to pharmacogenomics. Int J Mol Sci. 2017; 18(3), doi: 10.3390/ /ijms18030551, indexed in Pubmed: 28273839.

8. Calvey T, Patzke N, Bennett NC, et al. Nuclear organisation of some immunohistochemically identifiable neural systems in five species of insectivore-Crocidura cyanea, Crocidura olivieri, Sylvisorex ollula, Paraechinus aethiopicus and Atelerix frontalis. J Chem Neuroanat. 2016; 72: 34-52, doi: 10.1016/j.jchemneu.2015.12.012, indexed in Pubmed: 26724499.

9. Calvey T, Patzke N, Kaswera C, et al. Nuclear organisation of some immunohistochemically identifiable neural systems in three Afrotherian species - Potomogale velox, Amblysomus hottentotus and Petrodromus tetradactylus. J Chem Neuroanat. 2013; 50-51: 48-65, doi: 10.1016/j. jchemneu.2013.01.002, indexed in Pubmed: 23517750.

10. Calvey T, Patzke N, Kaswera-Kyamakya C, et al. Organization of cholinergic, catecholaminergic, serotonergic and orexinergic nuclei in three strepsirrhine primates: Galago demidoff, Perodicticus potto and Lemur catta. J Chem Neuroanat. 2015; 70: 42-57, doi: 10.1016/j. jchemneu.2015.10.002, indexed in Pubmed: 26562782.

11. Cavalcanti JR, Pontes ALB, Fiuza FP, et al. Nuclear organization of the substantia nigra, ventral tegmental area and retrorubral field of the common marmoset (Callithrix jacchus): A cytoarchitectonic and TH-immunohistochemistry study. J Chem Neuroanat. 2016; 77: 100-109, doi:10.1016/j.jchemneu.2016.05.010, indexed in Pubmed: 27292410. 
12. Cavalcanti JR, Soares JG, Oliveira FG, et al. A cytoarchitectonic and $\mathrm{TH}$-immunohistochemistry characterization of the dopamine cell groups in the substantia nigra, ventral tegmental area and retrorubral field in the rock cavy (Kerodon rupestris). J Chem Neuroanat. 2014; 55: 58-66, doi:10.1016/j.jchemneu.2014.01.002, indexed in Pubmed: 24444614.

13. Chudasama Y, Robbins TW. Dopaminergic modulation of visual attention and working memory in the rodent prefrontal cortex. Neuropsychopharmacology. 2004; 29(9): 1628-1636, doi: 10.1038/sj.npp.1300490, indexed in Pubmed: 15138446.

14. Cohen JY, Haesler S, Vong L, et al. Neuron-type-specific signals for reward and punishment in the ventral tegmental area. Nature. 2012; 482(7383): 85-88, doi: 10.1038/ /nature10754, indexed in Pubmed: 22258508.

15. Crutcher KA, Humbertson AO. The organization of monoamine neurons within the brainstem of the Northamerican opossum (Didelphis virginiana). J Comp Neurol. 1978; 179(1): 195-221, doi: 10.1002/cne.901790112, indexed in Pubmed: 8980724.

16. Dahlstroem A, Fuxe K. Evidence for the existence of monoamine-containing neurons in the central nervous system. I. Demonstration of monoamines in the cell bodies of brain stem neurons. Acta Physiol Scand Suppl. 1964; 232((suppl.)): 1-55, indexed in Pubmed: 14229500.

17. Dwarika S, Maseko BC, Ihunwo AO, et al. Distribution and morphology of putative catecholaminergic and serotonergic neurons in the brain of the greater canerat, Thryonomys swinderianus. J Chem Neuroanat. 2008; 35(1): 108-122, doi: 10.1016/j.jchemneu.2007.08.005, indexed in Pubmed: 17884333.

18. Fearnley JM, Lees AJ. Ageing and Parkinson's disease: substantia nigra regional selectivity. Brain J Neurol. 1991; 114 (Pt 5): 2283-2301, indexed in Pubmed: 1933245.

19. Feldhamer GA, Drickamer LC, Vessey SH. Mammalogy: Adaptation, Diversity, Ecology. 4th ed. John Hopkins University Press, Baltimore, Maryland 2015.

20. Fields HL, Hjelmstad GO, Margolis EB, et al. Ventral tegmental area neurons in learned appetitive behavior and positive reinforcement. Ann Rev Neurosci. 2007; 30: 289-316, doi: 10.1146/annurev.neuro.30.051606.094341, indexed in Pubmed: 17376009.

21. Flannery TF. Possums of the world: a monograph of the Phalangeroidea. GEO Productions in association with the Australian Museum 1994.

22. François C, Yelnik J, Tandé D, et al. Dopaminergic cell group A8 in the monkey: anatomical organization and projections to the striatum. J Comp Neurol. 1999; 414(3): 334-347, indexed in Pubmed: 10516600.

23. Fu $Y$, Yuan $Y$, Halliday $G$, et al. A cytoarchitectonic and chemoarchitectonic analysis of the dopamine cell groups in the substantia nigra, ventral tegmental area, and retrorubral field in the mouse. Brain Struct Funct. 2012; 217(2): 591-612, doi: 10.1007/s00429-011-0349-2, indexed in Pubmed: 21935672.

24. Garver DL, Sladek JR. Monoamine distribution in primate brain. I Catecholamine-containing perikarya in the brain stem of Macaca speciosa. J Comp Neurol. 1975; 159(3): 289-304, doi: 10.1002/cne.901590302, indexed in Pubmed: 1112914.
25. Gaspar P, Berger B, Gay M, et al. Tyrosine hydroxylase and methionine-enkephalin in the human mesencephaIon. Immunocytochemical localization and relationships. J Neurol Sci. 1983; 58(2): 247-267, indexed in Pubmed: 6131945.

26. Gerfen $C R$, Herkenham M, Thibault J. The neostriatal mosaic: II. Patch- and matrix-directed mesostriatal dopaminergic and non-dopaminergic systems. J Neurosci. 1987; 7(12): 3915-3934, indexed in Pubmed: 2891799.

27. German DC, Manaye KF. Midbrain dopaminergic neurons (nuclei A8, A9, and A10): three-dimensional reconstruction in the rat. J Comp Neurol. 1993; 331(3): 297-309, doi: 10.1002/cne.903310302, indexed in Pubmed: 8514911.

28. Gibb WR, Lees AJ. Anatomy, pigmentation, ventral and dorsal subpopulations of the substantia nigra, and differential cell death in Parkinson's disease. J Neurol Neurosurg Psychiatry. 1991; 54(5): 388-396, indexed in Pubmed: 1865199.

29. González-Hernández T, Rodríguez M. Compartmental organization and chemical profile of dopaminergic and GABAergic neurons in the substantia nigra of the rat. J Comp Neurol. 2000; 421(1): 107-135, indexed in Pubmed: 10813775.

30. Gundersen HJ, Bendtsen TF, Korbo L, et al. Some new, simple and efficient stereological methods and their use in pathological research and diagnosis. APMIS. 1988; 96(5): 379-394, indexed in Pubmed: 3288247.

31. Hardman CD, Henderson JM, Finkelstein DI, et al. Comparison of the basal ganglia in rats, marmosets, macaques, baboons, and humans: volume and neuronal number for the output, internal relay, and striatal modulating nuclei. J Comp Neurol. 2002; 445(3): 238-255, indexed in Pubmed: 11920704.

32. Hazlett JC, Ho RH, Martin GF. Organization of midbrain catecholamine-containing nuclei and their projections to the striatum in the North American opossum, Didelphis virginiana. J Comp Neurol. 1991; 306(4): 585-601, doi: 10.1002/ /cne.903060405, indexed in Pubmed: 1677010.

33. Hökfelt $T$, Johansson $O$, Fuxe $K$, et al. Immunohistochemical studies on the localization and distribution of monoamine neuron systems in the rat brain. I. Tyrosine hydroxylase in the mes- and diencephalon. Med Biol. 1976; 54(6): 427-453, indexed in Pubmed: 12423

34. Hökfelt T, Martensson R, Björklund A, et al. Distributional maps of tyrosine-hydroxylase-immunoreactive neurons in the rat brain. 1984

35. Jones HM, Pilowsky LS. Dopamine and antipsychotic drug action revisited. Br J Psychiatry. 2002; 181: 271-275, indexed in Pubmed: 12356650.

36. Keebaugh AC, Thomas JW. The genomes of the South American opossum (Monodelphis domestica) and platypus (Ornithorhynchus anatinus) encode a more complete purine catabolic pathway than placental mammals. Comp Biochem Physiol Part D Genomics Proteomics. 2009; 4(3): 174-178, doi:10.1016/j.cbd.2009.02.003, indexed in Pubmed: 20161190.

37. Klejbor I, Ludkiewicz B, Wojcik S, et al. Correlation between dopaminergic phenotype and expression of calretinin in the midbrain nuclei of the opossum (Monodelphis domes- 
tica): an immunohistological study. Acta Neurobiol Exp. 2013; 73(4): 529-540, indexed in Pubmed: 24457643.

38. Kabbaj M, Devine DP, Savage VR, et al. Neurobiological correlates of individual differences in novelty-seeking behavior in the rat: differential expression of stress-related molecules. J Neurosci. 2000; 20(18): 6983-6988, indexed in Pubmed: 10995843.

39. Karantanis NE, Youlatos D, Rychlik L. Diagonal gaits in the feathertail glider Acrobates pygmaeus (Acrobatidae, Diprotodontia): Insights for the evolution of primate quadrupedalism. J Hum Evol. 2015; 86: 43-54, doi: 10.1016/j. jhevol.2015.06.007, indexed in Pubmed: 26204798.

40. Kruger JL, Dell LA, Bhagwandin A, et al. Nuclear organization of cholinergic, putative catecholaminergic and serotonergic systems in the brains of five microchiropteran species. J Chem Neuroanat. 2010; 40(3): 210-222, doi: 10.1016/j. jchemneu.2010.05.007, indexed in Pubmed: 20566329.

41. Kruger JL, Patzke N, Fuxe K, et al. Nuclear organization of cholinergic, putative catecholaminergic, serotonergic and orexinergic systems in the brain of the African pygmy mouse (Mus minutoides): organizational complexity is preserved in small brains. J Chem Neuroanat. 2012; 44(1): 45-56, doi:10.1016/j.jchemneu.2012.04.002, indexed in Pubmed: 22554581

42. Limacher A, Bhagwandin A, Fuxe K, et al. Nuclear organization and morphology of cholinergic, putative catecholaminergic and serotonergic neurons in the brain of the Cape porcupine (Hystrix africaeaustralis): increased brain size does not lead to increased organizational complexity. J Chem Neuroanat. 2008; 36(1): 33-52, doi: 10.1016/j. jchemneu.2008.03.007, indexed in Pubmed: 18472246.

43. Lindvall $O$, Björklund $A$. The organization of the ascending catecholamine neuron systems in the rat brain as revealed by the glyoxylic acid fluorescence method. Acta Physiol Scand Suppl. 1974; 412: 1-48, indexed in Pubmed: 4531814.

44. Ma TP, Hazlett JC. Cytoarchitecture of the substantia nigra pars lateralis in the opossum (Didelphis virginiana): a correlated light and electron microscopic study. Anat Rec. 1995; 241(4): 563-578, doi: 10.1002/ar.1092410414, indexed in Pubmed: 7604970.

45. Manger PR. Establishing order at the systems level in mammalian brain evolution. Brain Res Bull. 2005; 66(4-6): 282-289, doi:10.1016/j.brainresbull.2005.05.002, indexed in Pubmed: 16144603.

46. Marcos P, Arroyo-Jimenez MM, Lozano G, et al. Mapping of tyrosine hydroxylase in the alpaca (Lama pacos) brainstem and colocalization with CGRP. J Chem Neuroanat. 2011; 41(2): 63-72, doi: 10.1016/j.jchemneu.2010.10.002, indexed in Pubmed: 21050884.

47. Marcos P, Arroyo-Jiménez MM, Lozano G, et al. Mapping of tyrosine hydroxylase in the diencephalon of alpaca (Lama pacos) and co-distribution with somatostatin-28 (1-12). J Chem Neuroanat. 2013; 50-51: 66-74, doi: 10.1016/j. jchemneu.2013.02.006, indexed in Pubmed: 23474224.

48. Maseko BC, Manger PR. Distribution and morphology of cholinergic, catecholaminergic and serotonergic neurons in the brain of Schreiber's long-fingered bat, Miniopterus schreibersii. J Chem Neuroanat. 2007; 34(3-4): 80-94, doi: 10.1016/j.jchemneu.2007.05.004, indexed in Pubmed: 17560075 .
49. McRitchie DA, Cartwright $\mathrm{H}$, Pond SM, et al. The midbrain dopaminergic cell groups in the baboon Papio ursinus. Brain Res Bull. 1998; 47(6): 611-623, indexed in Pubmed: 10078618.

50. McRitchie DA, Hardman CD, Halliday GM. Cytoarchitectural distribution of calcium binding proteins in midbrain dopaminergic regions of rats and humans. J Comp Neurol. 1996; 364(1): 121-150, doi: 10.1002/(SICI)10969861(19960101)364:1<121::AID-CNE11 >3.0.CO;2-1， indexed in Pubmed: 8789281.

51. Medeiros HH, Santana MA, Leite MD, et al. The cytoarchitectonic and $\mathrm{TH}$-immunohistochemical characterization of the dopamine cell groups in the substantia nigra, ventral tegmental area and retrorubral field in a bat (Artibeus planirostris). Neurosci Res. 2016; 112: 37-46, doi:10.1016/j.neures.2016.06.005, indexed in Pubmed: 27349153.

52. Moon DJ, Maseko BC, Ihunwo AO, et al. Distribution and morphology of catecholaminergic and serotonergic neurons in the brain of the highveld gerbil, Tatera brantsii. J Chem Neuroanat. 2007; 34(3-4): 134-144, doi: 10.1016/j. jchemneu.2007.06.001, indexed in Pubmed: 17606363.

53. Murray HM, Dominguez WF, Martinez JE. Catecholamine neurons in the brain stem of tree shrew (Tupaia). Brain Res Bull. 1982; 9(1-6): 205-215, indexed in Pubmed: 7172027.

54. Nicola SM, Taha SA, Kim SW, et al. Nucleus accumbens dopamine release is necessary and sufficient to promote the behavioral response to reward-predictive cues. Neuroscience. 2005; 135(4): 1025-1033, doi: 10.1016/j.neuroscience.2005.06.088, indexed in Pubmed: 16165291.

55. Nielsen MS, Sørensen JC, Bjarkam CR. The substantia nigra pars compacta of the Göttingen minipig: an anatomical and stereological study. Brain Struct Funct. 2009; 213(4-5): 481-488, doi: 10.1007/s00429-009-0217-5, indexed in Pubmed: 19705154.

56. Parent M, Parent A. Substantia nigra and Parkinson's disease: a brief history of their long and intimate relationship. Can J Neurol Sci. 2010; 37(3): 313-319, indexed in Pubmed: 20481265.

57. Paxinos G. The Rat Nervous System. Third Edition. Academic Press, Amsterdam, Boston 2004.

58. Paxinos G, Watson C. The Rat Brain in Stereotaxic Coordinates: Compact - 6th Edition [WWW Document]. https:// www.elsevier.com/books/the-rat-brain-in-stereotaxiccoordinates-compact/paxinos/978-0-12-374243-8 (accessed 7.2.17). 2008).

59. Pearson J, Goldstein M, Markey K, et al. Human brainstem catecholamine neuronal anatomy as indicated by immunocytochemistry with antibodies to tyrosine hydroxylase. Neuroscience. 1983; 8(1): 3-32, indexed in Pubmed: 6132348.

60. Phillipson OT. The cytoarchitecture of the interfascicular nucleus and ventral tegmental area of Tsai in the rat. J Comp Neurol. 1979; 187(1): 85-98, doi: 10.1002/ /cne.901870106, indexed in Pubmed: 489779.

61. Pillay S, Bhagwandin A, Bertelsen MF, et al. Regional distribution of cholinergic, catecholaminergic, serotonergic and orexinergic neurons in the brain of two carnivore species: The feliform banded mongoose (Mungos mungo) and the caniform domestic ferret (Mustela putorius furo). J Chem Neuroanat. 2017; 82: 12-28, 
doi: 10.1016/j.jchemneu.2017.04.001, indexed in Pubmed: 28416460.

62. Reyes S, Fu Y, Double K, et al. GIRK2 expression in dopamine neurons of the substantia nigra and ventral tegmental area. J Comp Neurol. 2012; 520(12): 2591-2607, doi: 10.1002/cne.23051, indexed in Pubmed: 22252428.

63. Russell R. Spotlight on Possums. University of Queensland Press, St Lucia 1980.

64. Russell R. Feathertail glider. In: Strahan R. (ed.). The Australian Museum complete book of Australian mammals. Collins Angus and Robertson, Sydney 1991: 170-171.

65. Seamans JK, Yang CR. The principal features and mechanisms of dopamine modulation in the prefrontal cortex. Prog Neurobiol. 2004; 74(1): 1-58, doi: 10.1016/j.pneurobio.2004.05.006, indexed in Pubmed: 15381316.

66. Smeets WJAJ, González A. Catecholamine systems in the brain of vertebrates: new perspectives through a comparative approach. Brain Res Brain Res Rev. 2000; 33(2-3): 308-379, indexed in Pubmed: 11011071.

67. Smith Y, Kieval JZ. Anatomy of the dopamine system in the basal ganglia. Trends Neurosci. 2000; 23(10 Suppl): S28-S33, indexed in Pubmed: 11052217.

68. Swanson LW. The projections of the ventral tegmental area and adjacent regions: a combined fluorescent retrograde tracer and immunofluorescence study in the rat. Brain Res Bull. 1982; 9(1-6): 321-353, indexed in Pubmed: 6816390.

69. Starck D. Lehrbuch der Speziellen Zoologie. Wirbeltiere. Teil 5: Säugetiere. Gustav Fischer Verlag, Jena 1995.

70. Tanaka C, Ishikawa M, Shimada S. Histochemical mapping of catecholaminergic neurons and their ascending fiber pathways in the rhesus monkey brain. Brain Res Bull. 1982; 9(1-6): 255-270, indexed in Pubmed: 7172030.

71. Torata Sano D. Beitrag zur vergleichenden Anatomie der Substantia nigra, des Corpus Luysii und der Zona incerta. (Fortsetzung.). Eur Neurol. 1910; 28(3): 269-278, doi: 10.1159/000209703.

72. Turner V, Mckay GM. Burramyidae. Fauna of Australia. Vol. 1B Mammalia (Walton DW, Richardson BC eds.). Australian Government Publishing Service, Canberra, Australia 1989: 652-664.

73. Tzschentke TM. Pharmacology and behavioral pharmacology of the mesocortical dopamine system. Prog Neurobiol. 2001; 63(3): 241-320, indexed in Pubmed: 11115727.

74. VandeBerg JL, Robinson ES. The Laboratory Opossum (Monodelphis Domestica) in Laboratory Research. ILAR J. 1997; 38(1): 4-12, indexed in Pubmed: 11528041.

75. Ward SJ. Reproduction in the Western Pygmy-Possum, Cercartetus concinnus (Marsupialia, Burramyidae), with notes on reproduction of some other small Possum Species. Austr J Zool. 1990; 38(4): 423, doi: 10.1071/zo9900423.

76. Wiklund L, Léger L, Persson M. Monoamine cell distribution in the cat brain stem. A fluorescence histochemical study with quantification of indolaminergic and locus coeruleus cell groups. J Comp Neurol. 1981; 203(4): 613-647, doi: 10.1002/cne.902030405, indexed in Pubmed: 7328202.

77. Woodside DP. Feathertail glider. In: Strahan R. (ed.). Mammals of Australia. Smithsonian Institution Press, Washington, D.C. 1995: 262-264.

78. Yamamoto K, Vernier P. The evolution of dopamine systems in chordates. Front Neuroanat. 2011; 5: 21, doi: 10.3389/ /fnana.2011.00021, indexed in Pubmed: 21483723. 